\title{
ARTICLE
}

\section{Natural rubber blocks as thermal neutron shields}

\author{
Orasa Onjun $^{\mathrm{a}^{*}}$, Nichapa Laothong $^{\mathrm{a}}$, Roppon Picha ${ }^{\mathrm{b}}$, Wichian Ratanathongchai ${ }^{\mathrm{b}}$ and Thawatchai Onjun ${ }^{\mathrm{c}}$ \\ ${ }^{a}$ Department of Science Service, Ratchathewi, Bangkok, 10400, Thailand; ${ }^{b}$ Thailand Institute of Nuclear Technology, Chatuchak, \\ Bangkok, 10900, Thailand; 'School of Manufacturing Systems and Mechanical Engineering, Sirindhorn International Institute of \\ Technology, Thammasat University, Phatum Thani, 12121, Thailand
}

Different amounts of boron compounds (i.e. boric acid and borax) are mixed with natural rubber to form a thermal neutron radiation shielding block. With proper treatment on natural rubber, uniform distribution of a boron compound can be achieved, which results in an enhancement of thermal neutron shielding capability. It is found that the neutron shield capability of those shielding blocks depends sensitively on both borax and boric acid's concentration, and the thickness of the shielding block. Even though the boron content in a natural rubber shielding block mixed with boric acid is higher than that with borax at the same amount, the shielding blocks with borax can shield thermal neutron better due to the loss of boric acid by a bubble formation during the process. An inclusion of lead oxide $\left(\mathrm{PbO}_{2}\right)$ in the shielding block can slightly increase its thermal neutron shielding capability and results in good gamma ray shielding capability, in which a minimum thickness of shielding blocks is required to be effective.

Keywords: natural rubber block; thermal neutron shielding; physical properties; borax; boric acid

\section{Introduction}

Ionizing radiation, like neutron or gamma ray, is used in many ways in laboratories, industries or hospitals. This could potentially yield a significant health hazard. Therefore, radiation protection is crucially needed for a safety measure. Generally, radiation protection aims to protect human, animals, and the environment from the harmful effects of ionizing radiation, including both particle radiation (neutron or electron) and high energy electromagnetic radiation (gamma or x-ray).

The development of materials with resistance to neutron radiation to protect personnel and instruments is important due to the need for neutrons in various applications and activities. For this propose, boron compounds are the most common substance used due to its large neutron cross-section [1-3]. In literature, shielding materials with different boron content have been studied by many research teams [4-7]. In this work, the study of two boron compounds (borax and boric acid) mixed with natural rubber as a shielding block for the attenuation of thermal neutron radiation is investigated. In addition, the inclusion of lead oxide $\left(\mathrm{PbO}_{2}\right)$ is considered, in which the effect on both neutron and gamma shielding is investigated.

*Corresponding author. Email: orasa@dss.go.th

\section{Experimental Set up}

\subsection{Shielding block preparation}

A thermal neutron radiation shielding block is developed using natural rubber as the base. Different amounts of boron compounds (i.e. boric acid and borax) are mixed with natural rubber to get shielding blocks with different concentrations. Three steps are used to prepare a shielding block, as shown in Figure 1. The "Mixing" step is done by using a two-roll mill and internal mixer (kneader) in order to mix natural rubber, boron compound, and other chemical compounds. Then, the boron mixed natural rubber is vulcanized by using sulfur compound. Finally, they are formed by using a heater.

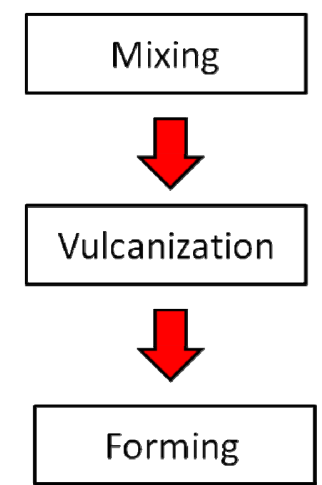

Figure 1. Three steps for natural rubber shielding block production. 
The formula used for each shielding block is shown in Table 1. The main chemical ingredients are provided.

Table 1. The chemical compounds used in this experiment ( $\mathrm{phr} .=$ parts per hundred rubber).

\begin{tabular}{|l|c|c|c|c|}
\hline \multirow{2}{*}{} & \multicolumn{4}{c|}{ Content (phr) } \\
\cline { 2 - 5 } Formulation & $\begin{array}{c}\text { Natural } \\
\text { Rubber }\end{array}$ & Borax & PbO2 & $\begin{array}{c}\text { Boric } \\
\text { acid }\end{array}$ \\
\hline SNB00 & 100 & - & - & - \\
\hline SNB10 & 100 & 10 & - & - \\
\hline SNB50 & 100 & 50 & - & - \\
\hline SNB100 & 100 & 100 & - & - \\
\hline SNB100L100 & 100 & 100 & 100 & - \\
\hline SNBa100 & 100 & - & - & 100 \\
\hline SNBa150 & 100 & - & - & 150 \\
\hline SNBa200 & 100 & - & - & 200 \\
\hline
\end{tabular}

\subsection{Radiation measurements}

In this work, an americium-beryllium combination $\left(\mathrm{Am}^{241} / \mathrm{Be}\right)$ is used as a neutron source, which radiates fast neutrons. These fast neutrons are slowed down to thermal neutrons by using their interactions with hydrogen in paraffin. Once thermal neutrons are obtained, they are directed onto a boron mixed natural shielding block, in which either a boron trifluoride $\left(\mathrm{BF}_{3}\right)$ proportional counter or a Geiger-Muller (GM) counter is placed behind to measure neutrons and gamma rays, respectively. A simple diagram is shown in Figure 2 below:

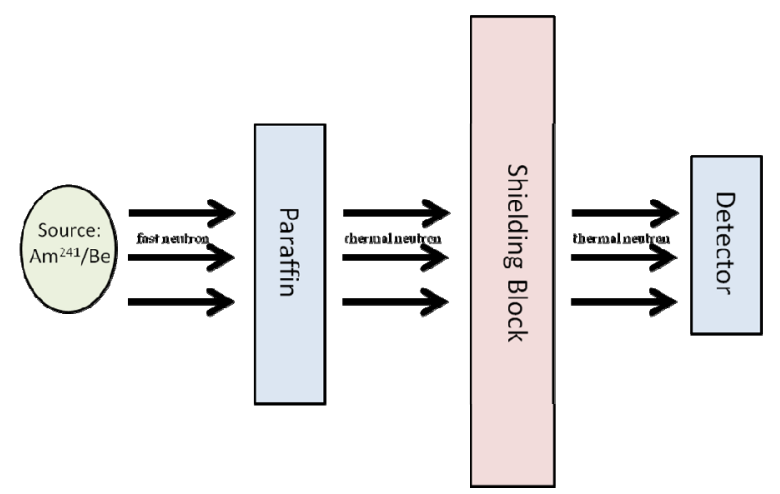

Figure 2. The experimental setup is designed to detect both thermal neutrons and gamma rays.

\section{Results and discussion}

\subsection{Thermal neutron attenuation}

Figure 3 shows the neutron counts obtained from a $\mathrm{BF}_{3}$ counter within $100 \mathrm{sec}$ for natural rubber shielding blocks mixed with different contents of either borax (top panel) and boric acid (bottom panel) as a function of the block thickness. It can be seen that natural blocks mixed with either borax or boric acid can shield the thermal neutron radiation. As the content of either borax or boric acid increase, the shielding capability increases. This can be understood by the increase of boron content, which results in thermal neutron shielding enhancement.

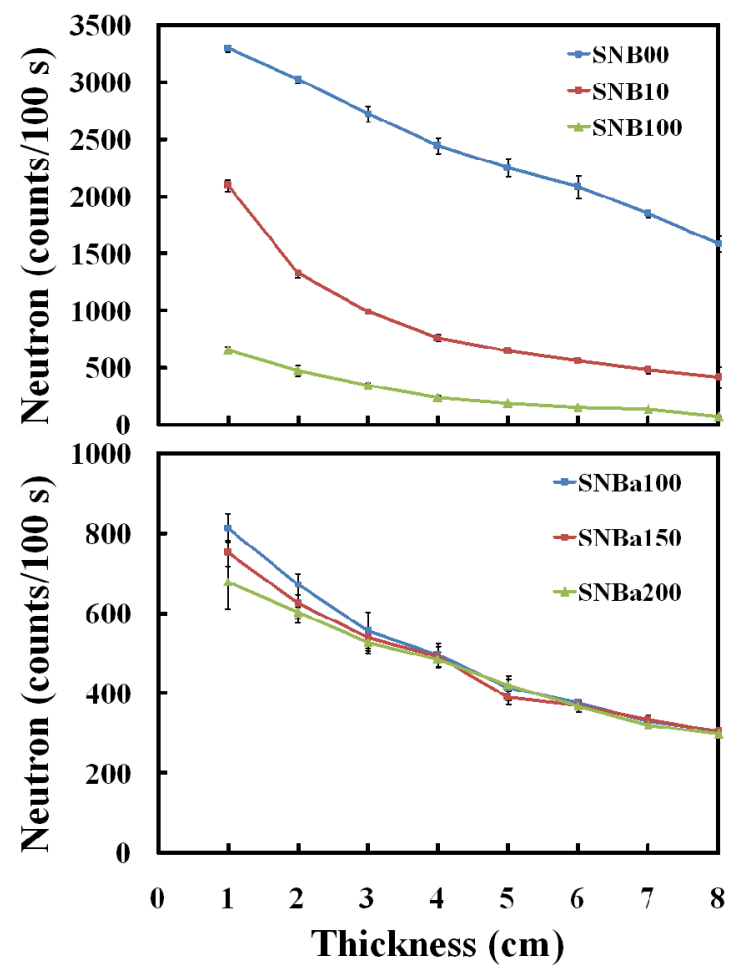

Figure 3. The neutron counts for natural rubber shielding blocks mixed with borax (top) and boric acid (bottom).

The comparison of thermal neutron capability is shown in Figure 4. In theory, boric acid has higher boron content than borax (17\% for boric acid and $11 \%$ for borax). As a result, natural rubber mixed with boric acid is supposed to shield thermal neutron better than that with borax. However, it can be seen in Figure 4 that the natural rubber shielding block mixed with borax can shield better. This could be explained with the loss of boric acid during the forming process. It is worth noting that there are bubbles occurred during the "forming" process. Also, it can be seen that when $\mathrm{PbO}_{2}$ is mixed with borax, the thermal neutron shielding capability slightly increases. Note that $\mathrm{PbO}_{2}$ can be used as gamma ray shielding. The increase of thermal neutron shielding can be understood by the increase of density.

Figure 5 shows the gamma counts obtained from the GM counter within $60 \mathrm{sec}$ with natural rubber shielding blocks mixed with borax at $100 \mathrm{phr}$. It can be seen that the gamma count decreases slowly for the block thickness up to $6 \mathrm{~cm}$ and decreases rapidly for the block thickness greater than $6 \mathrm{~cm}$. For this aspect, it depends on the gamma ray production and the shielding effectiveness. This contrasts with the neutron shielding capability, demonstrated by the slope, is quite high for the block thickness up to $6 \mathrm{~cm}$ and it is quite small as the block 


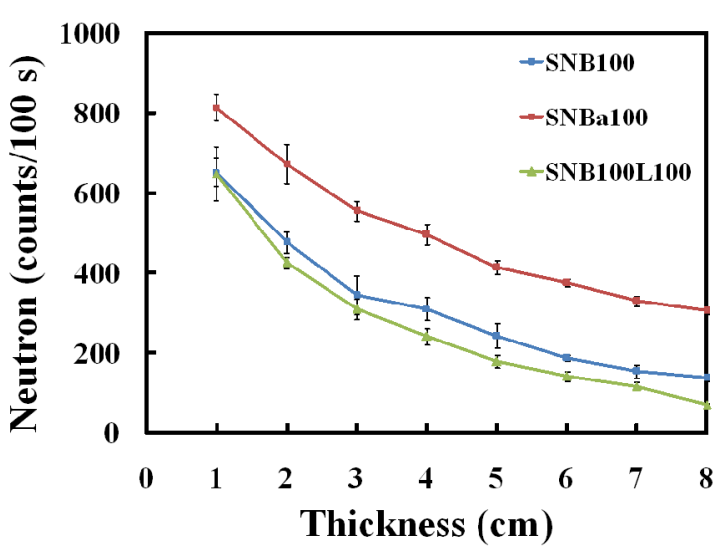

Figure 4. The neutron counts obtained for natural rubber shielding blocks mixed with borax (blue), boric acid (red), and combination of borax and $\mathrm{PbO}_{2}$ (green).

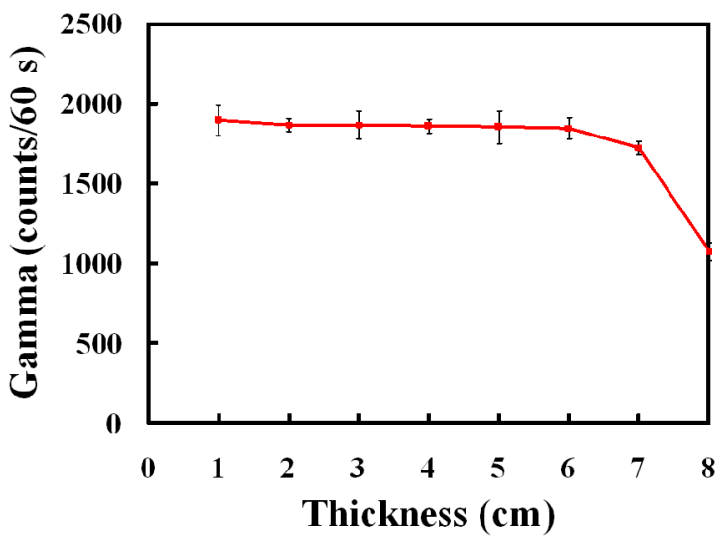

Figure 5. The gamma counts obtained for natural rubber shielding blocks mixed with combination of borax and $\mathrm{PbO}_{2}$.

thickness greater than $6 \mathrm{~cm}$.

\subsection{Particle distribution}

The particle distribution is one of the key issues for a neutron shielding. A uniform distribution of boron compound can result in better neutron shielding performance. In this work, the Scanning Electron Microscope (SEM) technique is used to investigate the distribution of boron compounds. Figure 6 shows the SEM on the natural rubber shielding blocks mixed with only borax, only $\mathrm{PbO}_{2}$, and a combination of borax and $\mathrm{PbO}_{2}$. It can be seen that both borax and $\mathrm{PbO}_{2}$ are uniform distributed, which is confirmed at higher magnification in Figure 7. It can also be noticed that the size of borax's particles is larger than that for $\mathrm{PbO}_{2}$.

\section{Conclusion}

Either boric acid or borax is mixed with natural rubber to form a thermal neutron radiation shielding block. Uniform distribution of boron compounds can be achieved in the natural rubber shielding blocks, which results in good thermal neutron shielding capability. It is found that neutron shield capability depends sensitively

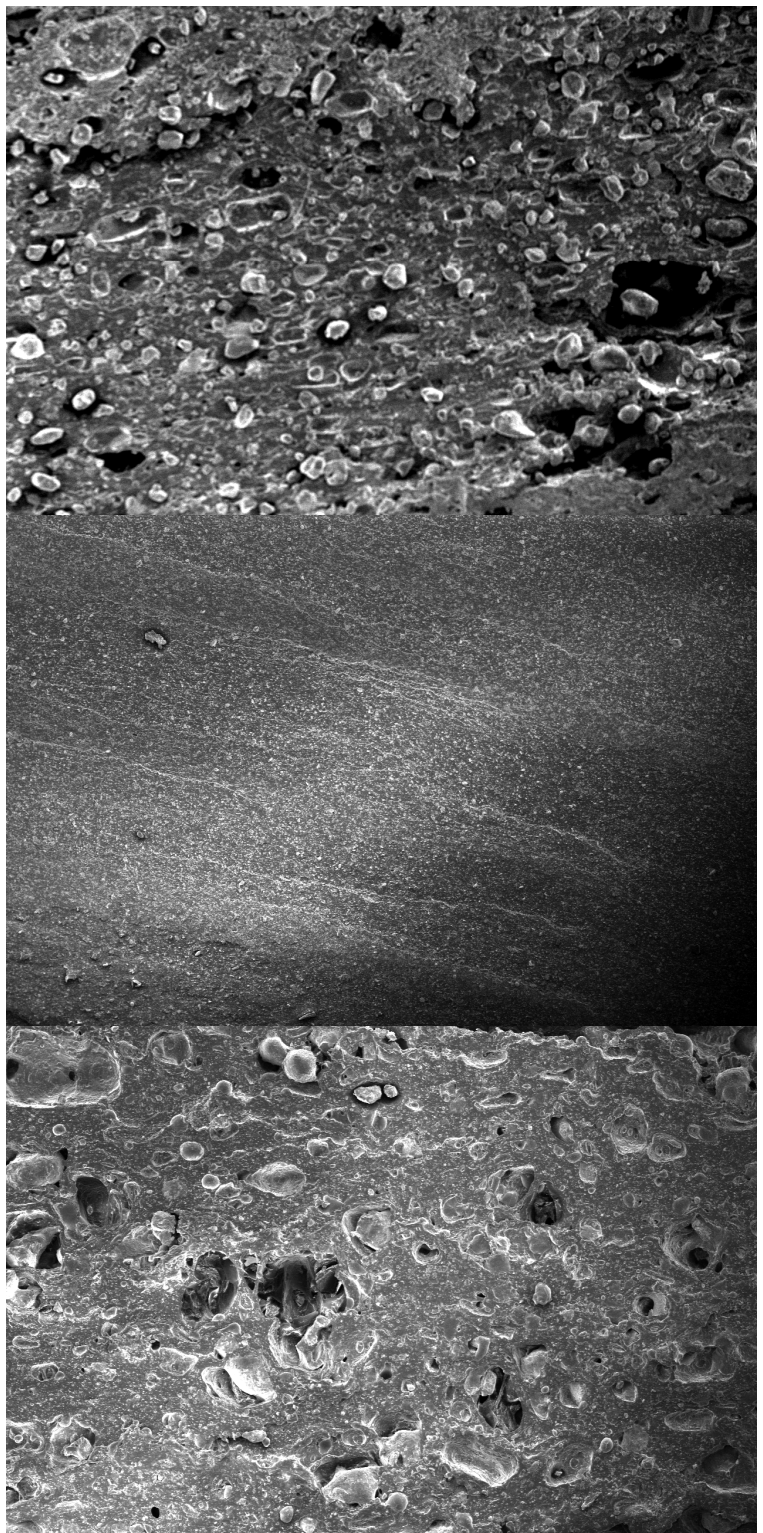

Figure 6. SEM images of the natural rubber shielding blocks mixed with only borax (top), only $\mathrm{PbO}_{2}$ (middle), and a combination of borax and $\mathrm{PbO}_{2}$ (bottom) at magnification of 30 .

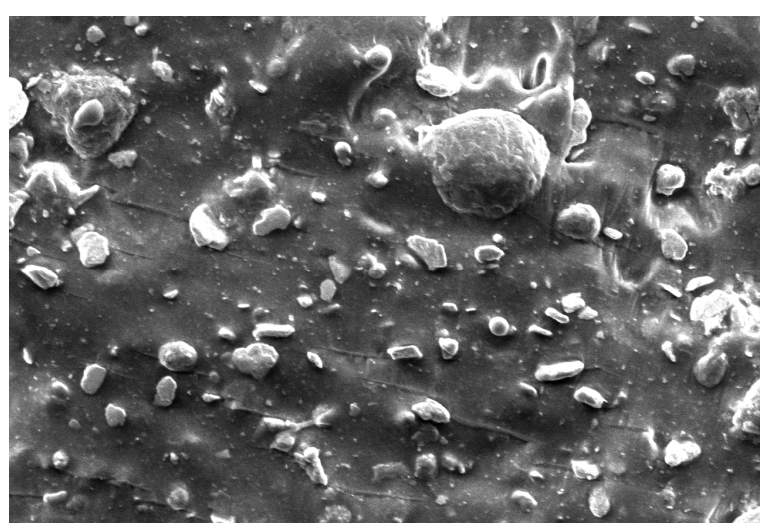

Figure 7. SEM images of the natural rubber shielding blocks mixed with a combination of borax and $\mathrm{PbO}_{2}$ at magnification of 1000 . 
on the boron concentration and the thickness of the shielding block. Even though boron content for boric acid is higher than borax at the same content, the shielding block with borax can shield thermal neutrons better.

\section{Acknowledgements}

The authors thank Department of Science Service (DSS) and Thailand Institute of Nuclear Technology (TINT) for financial support.

\section{References}

[1] A.B. Chilton, J.K. Shultis and R.E. Faw, Principles of Radiation Shielding, Prentice-Hall, Englewood Cliffs, NJ, (1984).
[2] J.K. Shultis and R.E. Faw, Radiation Shielding, Prentice Hall, Englewood Cliffs, NJ, (1996).

[3] B.T. Price, C.C. Horten and K.T. Spinnery, Radiation Shielding, Pergamon, Elmsford, NY, (1957).

[4] Y. Harada and H. Nakahara, INPADDOC, JP patent application 1-146620 (1989) [in Japanese].

[5] A. El-Khatib, M. Kassem and A.A. Ezzat, J. Polym. Mater. 7(1) (1990).

[6] K. Matsuda, H. Nishikowa and H. Harada, INPADOC, JP patent application, 63-716 (1988). [in Japanese]

[7] W.B. Kraus, M.B. Glasgow, M.Y. Kim, D.L. Olmeijer, R.L. Kiefer, R.A. Orwoll and S.A. Thibeault, Anon-205 ${ }^{\text {th }}$ ACS National Meeting, Washington, USA, 273 Paper, Polymer 23 (1993). 